\title{
Ensinando o pensamento computacional usando linguagens de programação no Alto Sertão da Paraíba
}

\author{
Felipe Torres $^{1}$, Mauro Junior ${ }^{1}$, Raucy Dantas ${ }^{1}$, Lucas Mascena ${ }^{1}$, Adriana Damasceno ${ }^{1}$ \\ ${ }^{1}$ Centro de Ciencia e Tecnologia Agroalimentar - UFCG \\ Rua Jario Vieira Feitosa - 58.840-000 - Pombal - PB - Brazil \\ \{felipe.alves.torres7, mauro.jnior7, adriana.damasceno\}@gmail.com
}

\begin{abstract}
Society uses computers in many sectors. However, computational thinking is one of the basis for its correct usage, and courses about this subject are rare, especially in regions far from state capitals. Also, Employing professionals at market is affected by this situation. This paper describes the offering of courses on computational thinking for students from high school at Paraiba countryside. We offered 140 positions during a two-year period, 89 students finished the course, and we present information regarding students socioeconomic level and how the courses helped on their empregability.
\end{abstract}

Resumo. Os computadores são empregados em todos os setores da sociedade e o pensamento computacional é umas das bases para o desenvolvimento das potencialidades de seu uso. No entanto, treinamentos nesta área são raros, principalmente em regiões afastadas de grandes capitais. Isto dificulta a qualificação no mercado de trabalho. Este artigo relata a realização de cursos sobre o pensamento computacional para alunos do ensino médio no interior da Paraíba. Ofertamos 140 vagas ao longo de dois anos, com formação de 89 alunos e caracterizamos o público-alvo a nível socioeconômico, além de avaliar a eficácia do curso depois da inserção dos alunos no mercado de trabalho.

\section{Introdução}

Os computadores são peça-chave na maioria das atividades do dia a dia. Eles ajudam o ser humano a aproveitar sua capacidade cerebral, uma vez que podem funcionar como agenda, realizar cálculos complexos, auxiliar no aprendizado de novos assuntos e outras funções. Particularmente na educação, a difusão dos cursos à distância ultrapassa barreiras de tempo e espaço, dando oportunidades de capacitação aos mais diversos setores da sociedade [Valente et al. 1999].

Mesmo assim, a exclusão digital é um problema a ser enfrentado, principalmente nas comunidades de baixa renda, onde a falta de acesso a uma educação de qualidade caminha ao lado da falta de uso dos computadores. De acordo com uma pesquisa feita pelo CETIC no ano de 2016 [CET 2018], a porcentagem de domicílios no Brasil que possui computador de mesa, computador portátil e tablet são de 22\%, 29\% e 17\%, nesta ordem. Paralelamente, a Paraíba carece de políticas de capacitação locais. O IDHM (Índice de Desenvolvimento Humano Municipal) é um índice que mede a longevidade, grau de educação e renda de um setor populacional. Na Paraíba, este índice é de 0,555, enquanto que nas cidades de Pombal, este número é 0,515 [ATL 2018]. Mais especificamente no Alto Sertão da Paraíba, um trabalho [Damasceno et al. 2016] constatou que as escolas 
VII Congresso Brasileiro de Informática na Educação (CBIE 2018)

Anais do XXIV Workshop de Informática na Escola (WIE 2018)

possuem laboratórios de informática, professores e alunos com conhecimento sobre o uso dos computadores, mas estes não são usados como ferramenta pedagógica em sala de aula.

Neste contexto, o pensamento computacional é um grande aliado para a melhoria da inclusão digital. O pensamento computacional é o conjunto de processos que permite a um sujeito resolver um problema analogamente a um cientista da computação. Este conceito representa os mecanismos envolvidos na formulação de problemas e suas soluções de forma que elas possam ser suportadas por uma agente computacional [Wing 2008]. Este processo de solução de problemas inclui o uso do computador ou outras ferramentas similares, implementar soluções possíveis para atingir os passos e recursos mais eficientes e generalizar uma solução para uma variedade maior de problemas [IST 2011].

Programas de qualificação para o uso dos computadores ajudariam a diminuir os impactos causados pela exclusão digital. Vários cursos sobre o pensamento computacional foram oferecidos, mas não foram usadas técnicas de avaliação ao longo do tempo. Identificamos cursos no Mato Grosso do Sul [Batista et al. 2016], São Paulo [Oli 2016], Bahia [Ramos and Teixeira 2015] e outras localidades do Brasil. Há iniciativas em algumas cidades da Paraíba [Scaico et al. 2013, Lopes et al. 2016] e um curso de introdução à informática foi oferecido em Pombal [Damasceno et al. 2011], mas não foram oferecidos cursos sobre pensamento computacional nas cidades de Pombal, São Domingos e Cajazeirinhas, todos no Alto Sertão.

Os objetivos deste trabalho são relatar e avaliar o oferecimento de cursos de introdução ao pensamento computacional para estudantes do ensino médio no Alto Sertão da Paraíba, assim como estabelecer o perfil dos alunos frequentadores. Estes cursos proporcionaram a formação de 89 alunos, com a apresentação de conceitos como estruturas sequenciais, de seleção e repetição usando duas ferramentas específicas para este contexto. Ademais, foram aplicados questionários avaliativos para medir o nível de satisfação dos alunos em relação ao curso e sua eficácia para os que estão no mercado de trabalho.

\section{Referencial Teórico}

A inclusão digital permite a democratização do acesso aos meios computacionais. Para acontecer, ela precisa de três instrumentos básicos [Marques 2014]: dispositivos de conexão, acesso à internet e domínio dos softwares usados. Para que softwares complexos possam ser inseridos no cotidiano dos usuários, é necessário o desenvolvimento de habilidades de raciocínio inerentes à lógica de programação. Neste contexto, um grande aliado à inclusão digital é o pensamento computacional, atingindo diversas áreas e sendo reconhecido como o terceiro pilar da ciência, junto com a teoria e a experimentação [Wing 2008].

O pensamento computacional é o conjunto de processos que permite a um sujeito resolver um problema analogamente a um cientista da computação. Neste sentido, este conceito representa os mecanismos envolvidos na formulação de problemas e suas soluções de forma que elas possam ser suportadas por uma agente computacional [Wing 2008].

Várias são as ferramentas que auxiliam na construção do pensamento computacional, dentre as quais citamos Scratch e Librelogo por serem softwares livres e de fácil instalação em computadores pessoais. O Librelogo [lib 2017] é uma linguagem 
VII Congresso Brasileiro de Informática na Educação (CBIE 2018)

Anais do XXIV Workshop de Informática na Escola (WIE 2018)

de programação textual baseada em Python [Cannon 2014], com comandos similares ao inglês e faz parte da suíte de escritório LibreOffice. Ela possui recursos necessários à construção de figuras geométricas, incluindo configurações relacionadas à cores. Scratch [Marji 2014] é uma linguagem de programação visual desenvolvida pelo Massachusetts Institute of Technology (MIT). Ela é constituída de blocos gráficos que representam comandos clássicos de linguagens de programação convencionais [Marji 2014].

Com o objetivo de difundir o pensamento computacional, alguns cursos focaram em seu ensino em diversas regiões no país, mas, ao contrário do trabalho que relatamos, não houve iniciativas desta natureza no Sertão da Paraíba nem a caracterização do público participante através da aplicação de questionários de eficácia do curso depois de algum tempo que os alunos o realizaram. A partir daí, os alunos de escolas públicas se mantiveram fora do ciclo de aprendizado deste conteúdo. Além disso, nem todos os cursos focaram em estudantes do Ensino Médio, e não houve a utilização da ferramenta Librelogo em nenhum deles. A Tabela 1 mostra um resumo de algumas iniciativas no país.

\section{Métodos}

Este trabalho teve dois objetivos: (1) relatar o desenvolvimento do pensamento computacional em escolas públicas do Ensino Médio do Alto Sertão da Paraíba através do oferecimento de cursos de introdução à programação e (2) caracterizar a eficácia dos cursos para os alunos atendidos. Para isso, utilizamos as seguintes etapas correspondentes ao curso: (i) planejamento; (ii) ministração e (iii) avaliação. A atividade (i) foi realizada pelo coordenador do projeto, enquanto que as atividades (ii) e (iii) foram desempenhadas por tutores estudantes do Ensino Superior em cursos de Engenharia. Todos os artefatos do projeto foram armazenados em um site.

Na etapa um, o conteúdo programático do curso de 40h foi escolhido por ser adequado ao ensino dos assuntos abordados e por permitir o oferecimento de duas turmas por ano com aulas de 4 horas lecionadas aos sábados. O conteúdo programático é composto de estruturas sequenciais, de seleção e repetição. Neste momento, foram propostas e testadas várias ferramentas, das quais somente o Scratch e Librelogo foram usadas por serem mais fáceis de utilizar e serem ferramentas livres. Além disso, as duas ferramentas foram adotadas para que o Librelogo pudesse ser usado em níveis introdutórios do curso e o Scratch fosse usado em etapas intermediárias. No total, tivemos 4 aulas usando o Librelogo e 6 aulas com Scratch.

Os tutores foram responsáveis pela ministração das aulas da etapa dois. Como o projeto tem parceria com o SEBRAE, foram distribuídos modelos específicos de fichas de inscrição nas escolas participantes, as apostilas foram impressas usando recursos financeiros deste órgão e disponibilizadas em nosso site para serem usadas livremente. Todas as aulas foram compostas por exposição e explanação do conteúdo, seguidas de exercícios propostos para fixação e avaliação. Como não era necessário que o tutor que elaborou a aula também a ministrasse, o site do projeto conteve uma página específica para a alocação dos tutores líderes para cada dia de aula. Ademais, a comunicação entre os tutores e os alunos era feita através de grupos virtuais usando o Facebook ou WhatsApp. No encerramento do curso, os alunos que tiveram rendimento e frequência superior a $70 \%$ também obtiveram certificados. Este ponto de corte foi adotado por ser mais usual em universidades e escolas de ensino fundamental e médio. Além disso, houve a apresentação de 
VII Congresso Brasileiro de Informática na Educação (CBIE 2018)

Anais do XXIV Workshop de Informática na Escola (WIE 2018)

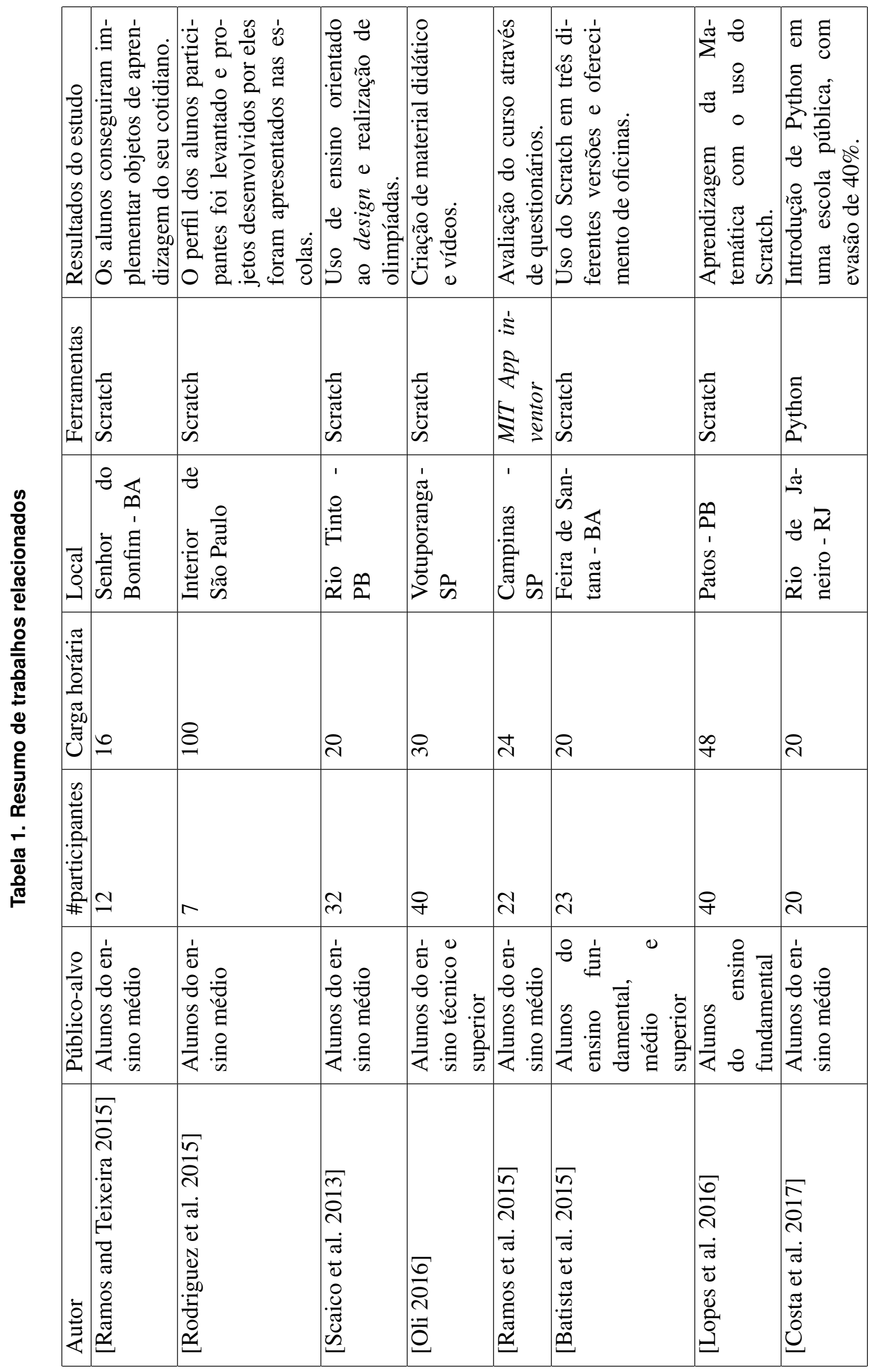


VII Congresso Brasileiro de Informática na Educação (CBIE 2018)

Anais do XXIV Workshop de Informática na Escola (WIE 2018)

projetos, aplicação dos questionários avaliativos do curso e entrega de certificados.

$\mathrm{Na}$ fase de avaliação (etapa três), a caracterização da eficácia dos cursos foi realizada. Para isso, três questionários foram aplicados com os seguintes objetivos: (i) avaliar o curso no último dia de aula, (ii) avaliar o impacto do curso na vida profissional dos participantes depois de 1 ano ou mais após seu término e (iii) estabelecer o perfil socioeconômico dos alunos. O questionário (i) da Figura 1 foi aplicado entre os concluintes sobre a satisfação e aprendizado dos alunos. Ele é composto de oito questões dicotômicas e uma questão discursiva.

1. As aulas começam e terminam pontualmente?

2. A estrutura do laboratório de informática é adequada à realização do curso?

3. Você está entendendo o conteúdo do curso?

4. Os tutores são prestativos?

5. Você acha que o conteúdo do curso vai ser usado na sua vida profissional?

6. Seu desempenho escolar melhorou depois de frequentar o curso?

7. Você gostaria de estudar assuntos mais avançados de programação?

8. Você acha que o curso tem alto nível de exigência?

9. Digite alguns comentários (sugestões, críticas) que você acha importante informar.

Figura 1. Questionário (i) (avaliativo do curso aplicado no último dia de aula)

O questionário (ii) da Figura 2 contém 21 questões com o objetivo de avaliar a percepção dos alunos participantes quanto à eficácia do curso após um ano e quais impactos a realização do curso trouxe para a inserção dos alunos no mercado de trabalho. As respostas usaram uma escala de 1-5, onde 1 representa discordo totalmente e 5 concordo totalmente.

O questionário (iii) foi aplicado para levantar o perfil socioeconômico dos alunos participantes para pesquisa de opinião e é composto de 11 questões com respostas fixas, mas diferentes entre si. A Figura 3 mostra as questões utilizadas com suas possibilidades de respostas.

\section{Resultados}

Os cursos de introdução à programação foram ofertados nos anos de 2015 e 2016 e atenderam alunos de escolas públicas de três cidades do Alto Sertão Paraibano, a saber: São Domingos, Pombal e Cajazeirinhas. As aulas foram realizadas aos sábados no laboratório de informática da universidade executora deste projeto. Esse horário foi escolhido para aproveitar a ociosidade do local e a disponibilidade dos tutores e alunos das escolas públicas. O laboratório conta com ambiente climatizado, quadro branco, datashow e 25 computadores com a seguinte configuração: 1 GB de memória RAM, 80 GB de HD e sistema operacional Windows XP.

Os cursos foram realizados em um turno, totalizando 40 horas cada. No ano de 2015 , foram ofertadas duas turmas de 20 alunos por semestre, totalizando 80 vagas. Deste total, tivemos 39 concluintes. No ano de 2016, foi ofertada uma turma de 30 vagas em cada semestre, totalizando 60 vagas e 50 concluintes. No total, houve desistência de 
VII Congresso Brasileiro de Informática na Educação (CBIE 2018)

Anais do XXIV Workshop de Informática na Escola (WIE 2018)

1. O curso de programação foi proveitoso para você?

2. Você trabalha na área em que se formou no curso de programação?

3. Antes de começar o curso, você já sabia ligar um computador?

4. Depois de terminar o curso, você aprendeu sobre o funcionamento do computador?

5. Você indicaria o curso para os seus colegas e amigos de escola?

6. Você pretende cursar o ensino superior na área de computação?

7. Foi importante para você realizar o curso de programação?

8. Sua expectativa após o curso foi alcançada?

9. Você acha que o curso foi proveitoso?

10. Você utiliza o aprendizado do curso no seu dia-a-dia?

11. Os tutores tinham capacidade de ensinar a você todo o conteúdo previsto ou restou alguma dúvida?

12. A infraestrutura do curso foi satisfatória? (sala de aula, datashow, computadores, etc).

13. Qual a importância da computação para a sua vida?

14. Após o curso de programação, a sua visão da área de Computação mudou?

15. Você voltaria a realizar outro curso nesta universidade?

16. A distância entre o local de realização do curso e sua casa prejudicou você?

17. Se o curso fosse realizado na sua própria escola, isso iria ajudar você?

18. Sua visão de computação melhorou após o curso?

19. Você sentiu dificuldade em aprender com os tutores do curso?

20. Qual curso você teria interesse em realizar conosco em uma nova oportunidade?

21. Você entende que a computação hoje é importante para a sua vida?

Figura 2. Questionário (ii) (avaliativo do curso aplicado após 1 ano)

$51,25 \%$ e 16,67\% dos alunos nos anos de 2015 e 2016, respectivamente. A alta porcentagem de desistência em 2015 ocorreu devido à ausência de transporte da prefeitura de São Bentinho e Cajazeirinhas, fazendo com que vários alunos não pudessem continuar assistindo aulas. Este problema foi corrigido no ano de 2016 através do oferecimento de vagas somente para alunos residentes na cidade do local do curso. A Figura 4 mostra o gráfico com o número de vagas ofertadas e alunos concluintes.

As aulas foram realizadas conforme seu planejamento. No último dia de curso, os alunos apresentaram trabalhos usando a ferramenta Scratch a fim de aplicar o conteúdo assimilado. Esta atividade foi realizada individualmente ou em duplas e resultou em diversas apresentações. Neste mesmo dia, o questionário (i) foi aplicado. As respostas evidenciaram em sua maioria feedback positivo do curso. A questão 9 é discussiva e por isso não pode ser apresentada no gráfico. No entanto, o conteúdo dos comentários continha elogios sobre o curso e críticas sobre infraestrutura oferecida pelo laboratório. A Figura 5 mostra o gráfico em barras para o percentual do número de respostas "sim"de cada questão nos anos de 2015 e 2016. A maioria das questões tiveram porcentagem de respostas em torno de $80 \%$, exceto as questões 6 e 8 . Com isso, conclui-se que a percepção dos alunos sobre o bom desempenho escolar e o nível de exigência do curso diminuíram. 
VII Congresso Brasileiro de Informática na Educação (CBIE 2018)

Anais do XXIV Workshop de Informática na Escola (WIE 2018)

1. Qual a sua idade? (menos de 16, 16-18, 19-21, 22-25, 26-30, mais de 30)

2. Informe seu sexo. (masculino, feminino)

3. Informe o rendimento total da sua família. (até 2 salários, 2-3, 3-5, 6-10, mais de 10)

4. Qual a sua participação na vida econômica de sua família? (não trabalha, trabalha e é independente, trabalha e não é independente, trabalha e sustenta a família)

5. Qual sua cor/ raça? (branca, preta, parda, amarela, indígena)

6. Possui computador em casa? (sim, não)

7. Qual foi seu meio de transporte para vir ao curso de programação? (carro, ônibus, a pé, outro)

8. Como você se identificou com a atividade de programar? (não me identifico, me identifico pouco/ razoalmente, me identifico, me identifico muito)

9. Você indicaria o curso para outros colegas? (não, indicaria pouco/ razoavelmente/ totalmente, indicaria)

10. Avalie a influência do seu desempenho escolar com a realização do curso. (não melhorou, melhorou pouco/ razoavelmente/ muito, melhorou)

11. Avalie a aplicabilidade do curso para o mercado de trabalho. (não vou usar, usarei pouco/ razoavelmente/ muito, usarei)

Figura 3. Questionário (iii) (socioeconômico dos alunos)

O questionário (ii) foi aplicado por telefone pelos tutores depois de mais e um ano de curso. No total, 89 ex-alunos foram contatados, mas como a participação era voluntária e vários números de telefone mudaram depois de mais de um ano de encerramento do curso, foram obtidas somente 59 entrevistas. A Figura 6 mostra as respostas da questões de acordo com a escala Likert, sendo que 1 representa discordo totalmente e 5 concordo totalmente. Do total de 20 questões, 15 tiveram mais de $90 \%$ de respostas do tipo 4 ou 5. Com isso, constata-se que há pouco interessem dos alunos em realizar cursos mais avançados na área de informática, eles não percebem aplicação dos cursos no dia-a-dia, a distância entre suas moradias e o local do curso prejudicou os alunos e não houve dificuldade em aprender com os tutores do curso. A questão 20 não é mostrada

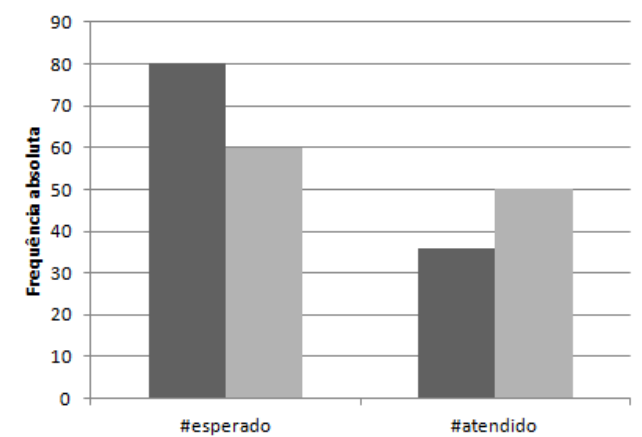

Figura 4. Oferecimento de vagas e desistência dos alunos

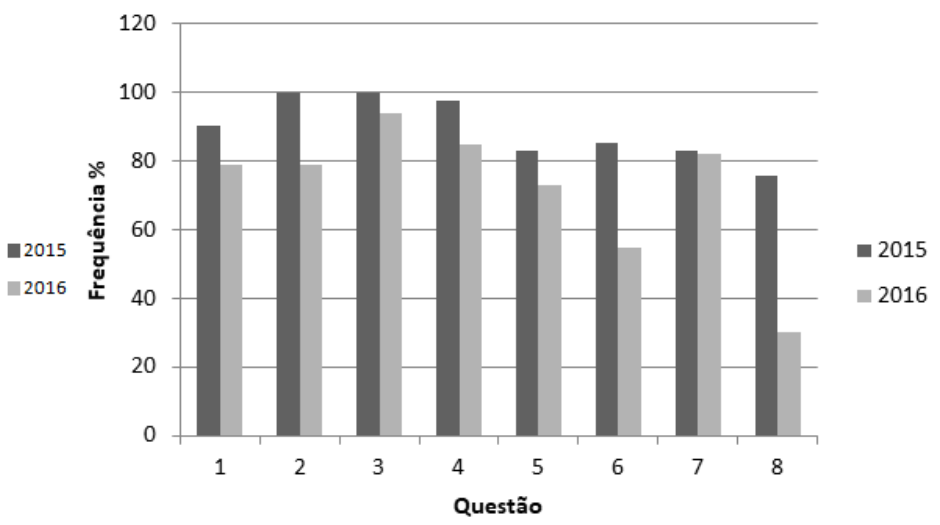

Figura 5. Respostas dos questionários avaliativos 
VII Congresso Brasileiro de Informática na Educação (CBIE 2018)

Anais do XXIV Workshop de Informática na Escola (WIE 2018)

porque foi aberta, mas a maioria dos respondentes informou que gostaria de participar de um curso mais avançado de programação.

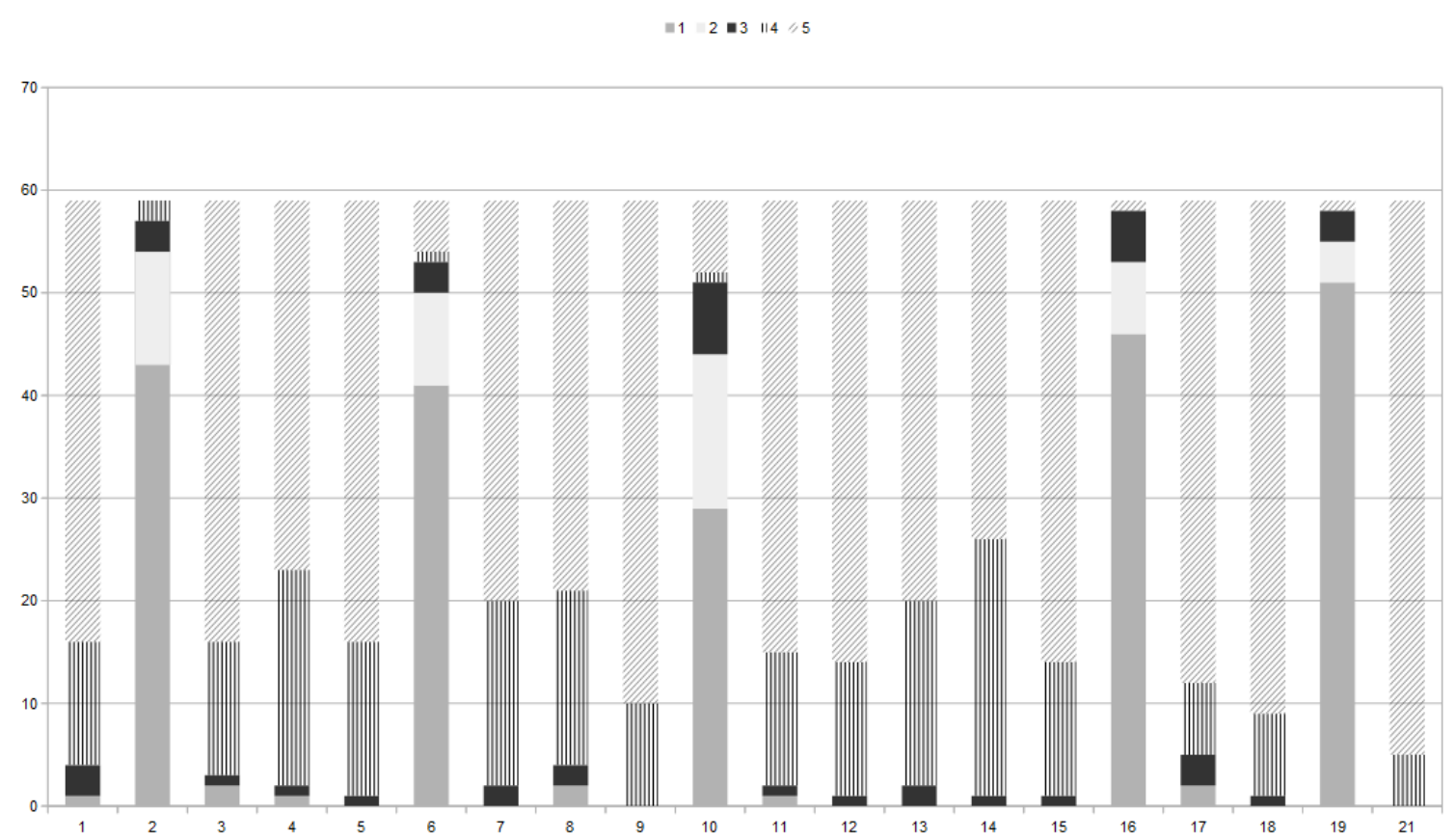

Figura 6. Respostas do questionário pós-curso

Também aplicamos o questionário (iii) online da Figura 3 para levantar o perfil socioeconômico dos alunos. Apesar de 89 alunos terem sido atendidos nos cursos, somente 19 responderam o questionário porque alguns faltaram e sua participação na entrevista foi voluntária. Como as respostas eram diferentes, não foi possível resumir as informações em um gráfico, sendo necessário usar texto discussivo. Do total de entrevistados, 5 possuem menos de 16 anos e 13 possuem entre 16 e 18 anos. Ademais, somente 2 são do sexo masculino, enquanto que 16 são do sexo feminino. Seguindo a sequência das questões, 1 aluno tem rendimento total familiar com mais de 5 e menos de 10 salários mínimos, 5 alunos têm renda com mais de 2 e menos de 3 salários e 12 possuem renda de até 2 salários mínimos. Com relação à participação na vida econômica da família, 1 aluno informou que trabalha, mas seus gastos são custeados, enquanto que os outros 17 alunos informaram que não trabalham e que seus gastos são custeados. Quando perguntados sobre sua cor/raça, 1 aluno declarou ter raça amarela, enquanto que 2 informaram serem brancos e os 15 restantes declararam serem pardos. Metade dos alunos possui computador em casa; 2 alunos usam moto como meio de transporte para ir ao curso contra 2 que vão a pé e 14 que usam ônibus; e todos indicariam o curso a outros colegas, sendo que 7 deles indicaria totalmente, 12 indicariam e somente 1 indicaria razoavelmente. Ainda quando perguntados sobre seu grau de identificação com a atividade de programar, 2 alunos informaram se identificar muito, 1 não se identifica, 1 se identifica pouco e 7 se identificam razoavelmente. Sobre a autopercepção de melhora no desempenho escolar, 1 aluno informou melhorar muito, 3 melhoraram razoavelmente, 9 alunos melhoraram, 5 alunos melhoraram pouco e 1 não melhorou. Na última pergunta, 1 aluno informa que usará razoavelmente o conteúdo do curso para o mercado de trabalho, enquanto que 7 usarão pouco e 11 usarão o conteúdo do curso. 
VII Congresso Brasileiro de Informática na Educação (CBIE 2018)

Anais do XXIV Workshop de Informática na Escola (WIE 2018)

Algumas considerações finais foram percebidas pelos tutores durante a ministração dos cursos. Nos momentos iniciais, houve a carência de habilidades do uso de computadores por parte dos alunos atendidos. Alguns inclusive tinham dificuldades claras até mesmo para digitação. Estas dificuldades precisaram ser sanadas ou, ao menos, compensadas pelos tutores para que o curso pudesse prosseguir. Apesar disto, os alunos conseguiram assimilar os conteúdos propostos e apresentaram avanços na realização dos exercícios, com maior facilidade na linguagem Scratch porque eles conseguiam visualizar os blocos de comandos e encaixá-los sequencialmente em instruções para formar os programas.

\section{Conclusões}

Este trabalho relatou a ministração de cursos no Alto Sertão da Paraíba sobre o pensamento computacional e sua eficácia durante a inserção dos alunos no mercado de trabalho. Dentre os resultados, oferecemos 140 vagas para alunos do ensino médio, formando 89 estudantes. Além disso, aplicamos questionários avaliativos e socioeconômicos do curso, sendo um dos questionários aplicados um ano depois de sua realização.

Dentre os achados, pudemos constatar em mais de um questionário que os alunos se autoavaliaram e informaram que seu desempenho escolar melhorou, mas não há demanda para cursos avançados de programação. Ademais, a maioria dos alunos informou que a realização do curso contribui para a melhoria de suas vidas profissionais e que pretendem usar o conteúdo do curso no mercado de trabalho. No entanto, a maioria não trabalha na área de Computação e não usa o conteúdo do curso no dia a dia.

Este relato de experiência contribuiu para o registro de metodologias de cursos sobre o pensamento computacional em cidades distantes das grandes capitais. Os trabalhos futuros incluem o oferecimento de cursos em outras cidades e a adaptação desta metodologia para que os cursos sejam ofertados pelos próprios alunos residentes nas cidades e os laboratórios das escolas sejam usados. Ademais, pretendemos aplicar entrevistas semiestruturadas para os egressos, de forma a descobrir outras características do público-alvo.

\section{Referências}

(2011). ISTE and CSTA. https://c.ymcdn.com/sites/www. csteachers. org/resource/resmgr/CompThinkingFlyer.pdf. Accessado: 18-012017.

(2016). Material didático lúdico: uso da ferramenta Scratch para auxílio no aprendizado de lógica da programação. In Anais do Workshop de Informática na Escola (WIE), volume 22, pages 359-368.

(2017). Librelogo.org. http:// librelogo.org/en/. Accessado: 18-01-2017.

(2018). ATLAS. http: / / atlasbrasil.org.br/. Accessado: 03-03-2018.

(2018). CETIC. http: // data. cetic.br/cetic/. Accessado: 03-03-2018.

Batista, E. J. S., Jr., A. C., Cantero, S., Bogarim, C. A. C., and Larrea, A. A. (2016). Uso do Scratch no ensino de programação em Ponta Porã: das séries inicias ao ensino superior. 22(1):565-574. 
VII Congresso Brasileiro de Informática na Educação (CBIE 2018)

Anais do XXIV Workshop de Informática na Escola (WIE 2018)

Batista, W. P., Chalegre, H. S., Sena, J. P. S., Santos, A. H. M., Santos, D. M. B., Rodrigues, C. A., and Bittencourt, R. A. (2015). Oficinas de Aprendizagem de Programação em uma Escola Pública através do Ambiente Scratch. In Workshop sobre Educação em Computação (WEI), pages 1-10.

Cannon, J. (2014). Python Programming for Beginners: An Introduction to the Python Computer Language and Computer Programming. CreateSpace Independent Publishing Platform.

Costa, A. C., Jullian, R., Mota, C. V. A., Franco, A. A., Muniz, V. H. J., Maia, L. d. L., and Liese, T. M. (2017). Python: Será que é possível numa escola pública de Ensino Médio? Anais do Workshop de Informática na Escola, 23(1):255.

Damasceno, A., Moreira, F., Santos, T., and Alvino, C. (2011). Inclusão digital na cidade de Pombal. In Workshop sobre Educação em Computação (WEI), pages 1689-1698.

Damasceno, A. C., Lopes, M., Andrade, R., Nobrega, S., and Almeida, I. (2016). Descrevendo o uso dos computadores nas escolas públicas da Paraíba. Revista Brasileira de Informática na Educação, 24(3):47-61.

Lopes, C. C., Duarte, M. d. S. d. S. G., Sousa, E. A. D., de Souza, R. P., and Pereira, I. B. (2016). O Ensino de Algoritmos e Lógica de Programação como uma Ferramenta Pedagógica para Auxiliar a Aprendizagem de Matemática: Um Relato de Experiência. In Anais do Workshop de Informática na Escola (WIE), volume 22, pages 41-50.

Marji, M. (2014). Learn to Program with Scratch: A Visual Introduction to Programming with Games, Art, Science, and Math. No Starch Press.

Marques, F. P. J. A. (2014). Democracia online e o problema da exclusão digital. Intexto - UFRGS, (30):93-113.

Ramos, F. and Teixeira, L. D. S. (2015). Significação da Aprendizagem Através do Pensamento Computacional no Ensino Médio: uma Experiência com Scratch. In Anais do Workshop de Informática na Escola (WIE), volume XXI, pages 217-226.

Ramos, N., Freitas, C., Avila, S., Costa, P. D. P., Testoni, V., and Borin, J. F. (2015). Ensino de Programação para Alunas de Ensino Médio : Relato de uma Experiência. In Workshop sobre Educação em Computação (WEI), pages 1-10.

Rodriguez, C., Zem-Lopes, A. M., Marques, L., and Isotani, S. (2015). Pensamento computacional: transformando ideias em jogos digitais usando o scratch. In Anais do Workshop de Informática na Escola (WIE), volume 21, page 62.

Scaico, P. D., de Lima, A. A., Azevedo, S., da Silva, J. B. B., Raposo, E. H., Paiva, L. F., Alencar, Y., Mendes, J. P., and Scaico, A. (2013). Ensino de Programação no Ensino Médio: Uma Abordagem Orientada ao Design com a linguagem Scratch. Revista Brasileira de Informática na Educação, 21(02):92.

Valente, J. A. et al. (1999). O computador na sociedade do conhecimento. Campinas: Unicamp/NIED, pages 11-18.

Wing, J. M. (2008). Computational thinking and thinking about computing. Philosophical transactions of the royal society of London A: mathematical, physical and engineering sciences, 366(1881):3717-3725. 